\title{
THE INFLUENCE OF LAP SIZE ON SHEAR STRENGTH OF ADHESIVE JOINTS
}

\author{
Andrzej Kubit ${ }^{1}$, Barbara Ciecińska' ${ }^{1}$, Kamil Drozd ${ }^{1}$ \\ 1 Department of Manufacturing Processes and Production Engineering, The Faculty of Mechanical Engineering \\ and Aeronautics, Rzeszow University of Technology, Powstanców Warszawy 12, 35-959 Rzeszow, Poland, \\ e-mail: akubit@prz.edu.pl; bcktmiop@prz.edu.pl; drozduwp@wp.pl
}

Received: 2015.04.10

Accepted: 2015.05 .08

Published: 2015.06.01

\begin{abstract}
Adhesive joints may be used instead of forced-in joints, welded and riveted joints, soldered and twisted connections. They are characterized by a lot of advantages, thanks to them the adhesive joints are willingly used in manufacturing processes. These advantages include low price of joint, reduction of weight of the final construction, improvement of durability, reliability and quality and improving visual appearance. From this point of view it should be concluded that experimental tests of adhesive joints are grounded. In the paper the results of experimental tests of static shear strength of single-lap joints are presented. These joints are made with two constructive glues. The specimens made from AISI 4130 steel were glued. Their surfaces were prepared in two versions before gluing: grinded with abrasive paper by hand and cleaned by sand-blasting. The results were analyzed from variable size of the lap point of view.
\end{abstract}

Keywords: adhesive joints, lap size, shear strength.

\section{INTRODUCTION}

Adhesive bonding consists of placing a thin layer of glue between bonded surfaces. This process allows to joint two objects with adhesive forces. Adhesive bonding also gives possibility to joint elements made from different materials - metallic with metals, ceramic, plastics or even glass. In practice it may be the only way to joint materials. Gluing is good manner to joint elements with different thickness or for such of them where jointing by other methods is impossible. Bonding a is simple and economic process, joints gives possibility to maintain high durability of construction, they do not provoke negative internal stresses because of small hardening shrinkage. The glue may function as a seal because of its chemical resistance. The modification of glue composition by fillers may lead to obtaining substances with unique characteristics. This special treatment may lead to significant changes of glue properties: they may be resistant to high temperature, conduct electricity or be dielectrics in reverse, have different flexibility, fatigue or impact strength, hardness, heat resistance or life. These modifications are sometimes used in joints whose temperature of exploitation changes in great degree [1].

The bonding process entails several basic operations. The steps of the creation of each joint are almost the same and it is important to follow them in a precisely defined order. There are:

- preparing surface before glue covering,

- preparing and spreading the glue

- jointing the surfaces

- glue hardening - the joint making

- the finishing and quality control of joint [2-4].

In adhesive bonding the correct pretreatment of the surface is important - it is deciding factor to achieve durable joint. Thanks to these operations the elimination of every kind of pollution on the surface is possible, e.g. dirt, fat, corrosion products, dust. The surface may also expand and may achieve its proper energy state $[2,5,6]$.

At present there are different ways of achieving technological effects described above. However, sometimes there are also some difficulties, e.g.: problematic inspection manners, the requirement 
of retain short time between the following activities, the necessity of keeping the tools and equipment clean [2].

Typical actions performed during the pretreatment of surfaces are:

- Degreasing - in order to remove fats, lubricants, dust, organic and non-organic substances. This step may be realized in the steams and liquids of solvents. Typical substances to this purpose are: acetone, ethylic alcohol or other alkaline chemicals emulsified the lubricants and grease $[2,6,7]$;

- Cleaning in acid or alkaline bath - it is removing oxides and scale from surfaces of the part; these layers are unnecessary and may lead to some problems in the next stage of surface pretreatment. Cleaning is conducting in the adjusted to the sort of material bath $[3,6,8]$;

- Rinsing - in acid or alkaline bath, sometimes it is carried out also after special treatment. It is aimed at removing remains of galvanic or cleaning bath, dust after special treatment. Cold or hot, demineralized or distilled water is use. Next, the surface should be cleaned in ethanol. Even small parts of etching bath determine corrosion or other negative reactions in glues and prime coats $[2,6,7]$.

- Drying - removing of remains of water from previously rinsed elements [2].

- Special treatment of surface - for preparing thin layers on the surfaces, they consist of salts (phosphates, fluorides, sulfates, nitrides, chromates, and other similar compounds), whose presence on the surfaces before gluing increases adhesive joints strength $[5,8]$.

- Coating with primer or glue - in time which lasts as short as possible. Parts with primer or other cover should be protected with fat-free paper and storing without the air access in the temperature $20^{\circ} \mathrm{C}[2,7]$.

All components should be mixed in correct proportions to receive gluing substance. The amount of glue and hardener, process of mixing and carefulness are important. In mixing of glues different kinds of mixers are used, this is a guarantee of precise in jointing different substances. Excess or lack of hardener and absence of thoroughness are the cause of low quality of joint. Then the joints may be soft, clammy and ductile or have low strength $[3,6,9]$. The consistency of adhesives and their homogeneity are the cause of quality of joint. Excess of glue gives thick joint which dries a long time and has poor strength. Lack of glue makes problems with wettability of surface, gives thin and poor joint [4].

During the activity with the preparing of gluing mass it is absolutely necessary not to making accidental bubbles. The heating and mechanical mixing gives good results in this. The bubbles in the joint reduce the strength about 5-15\% [3]. Another important problem is time of glue life. It starts while the mass is prepared and from this moment the adhesive properties depend in the joint. It is important also during the realization of technological process, while the sequence and length of operations are planning. After an opening of container with glue its properties are modified with time. What is more, length of life of glue is not synonyms to the time of storage $[3,6]$.

After the preparation of the mass the covering of jointed surfaces takes place. It is very important operation and its manner depends on the form of glue, its viscosity, shape of jointed elements or even on type of production [6].

During the surface covering by glue the same thickness, regular field and correct wettability are required. Elements may be heated for less viscosity and high wettability. Heating is required in the case of glue in a form of bars, solids or powder [8].

After the covering the surfaces by the glue the jointed parts should be connected to each other in the shortest time and fixed not yet hardened joint [10].

\section{THE METHODOLOGY OF EXPERIMENT}

Because of many problems in gluing the experimental research was conducted. The influence of size of lap on the shear strength of a single-lap joints was investigated. To the preparation of test pieces the constructional steel AISI 4130 consisted of C $(0,22-0,29 \%), \mathrm{Mn}(0,40-0,70 \%), \mathrm{Si}$ $(0,17-0,37 \%), \mathrm{Cr}(0,80-1,10 \%), \mathrm{Ni}(\leq 0,30 \%), \mathrm{Mo}$ $(0,15-0,25 \%), \mathrm{V}(\leq 0,05 \%), \mathrm{W}(\leq 0,20 \%), \mathrm{Ti}(\leq$ $0,05 \%), \mathrm{Cu}(\leq 0,25)$, As $(\leq 0,08 \%)$ was used [11]. This steel is applied in the manufacturing processes of loaded parts, exposed to hitting, torsion and vibration for example in aeronautics [12].

The test pieces were joined by Araldite 2011 and 2014-1 glues. These glues are characterized by long life time, high shear strength and tear off strength, static and dynamic load resistance. They are different in time of bonding and the proportion of epoxy resin to the hardener (Table 1) [11]. 
Table 1. The properties of epoxy resins Araldite 2011 and Araldite 2014-1 [11]

\begin{tabular}{|l|c|c|}
\hline \multicolumn{1}{|c|}{ Epoxy resin } & $\begin{array}{c}\text { Araldite } \\
2011\end{array}$ & $\begin{array}{c}\text { Araldite } \\
2014-1\end{array}$ \\
\hline Proportion of components & $1: 1$ & $2: 1$ \\
\hline Life time (min) & 100 & 60 \\
\hline Color (after mixing) & Wan-yellow & Grey \\
\hline Time of bonding $20^{\circ} \mathrm{C}(\mathrm{h})$ & 7 & 3 \\
\hline Time of hardening w $20^{\circ} \mathrm{C}(\mathrm{h})$ & 36 & 36 \\
\hline
\end{tabular}

For gluing the test pieces of dimensions $d \times l \times g$ : $25 \times 100 \times 1 \mathrm{~mm}$ with 5-repetition was made. Variable value was the length of lap $\mathrm{z}$ and it was: $z_{1}=8 \mathrm{~mm}, z_{2}=12,5 \mathrm{~mm}, z_{3}=16 \mathrm{~mm}, z_{4}=$ $24 \mathrm{~mm}$ (Fig. 1).

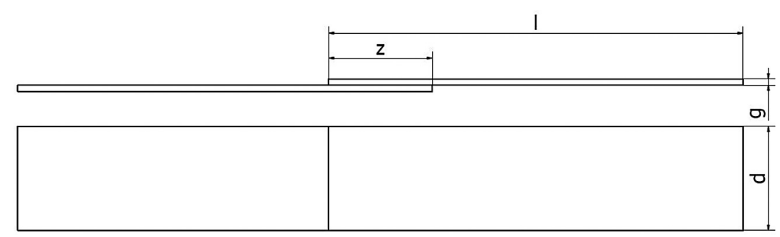

Fig. 1. The scheme of adhesive joint in the experiment
The surfaces before gluing were made in two options: treated by abrasive paper P80 and mechanically by sand-blast cleaning (corundum A90). Then the pieces were cleaned in acetone in ultrasonic washer and dried in room temperature. Next, the bonded pieces were placed into the special bonding holder for hardening the joints. After the jointing the test pieces were broken in the Zwick/Roell Z100 tensile testing machine.

\section{RESULTS}

In the experimental research the value of shear force $P_{t}$ was obtained. The mean value of $P_{t-m}$ and static shear strength $R_{t}$ from the relation (1) were calculated:

$$
R_{t}=P_{t-m} / A
$$

where: $A$ - the field of lap.

The results of tests and calculations are presented in the Tables 2-5. Mentioned below graphs

Table 2. The results for $z_{1}$

\begin{tabular}{|c|c|c|c|c|}
\hline \multirow{2}{*}{ Test piece number } & \multicolumn{4}{|c|}{ The length of lap: $\mathrm{z}_{1}=8 \mathrm{~mm} ; \mathrm{A}_{1}=200 \mathrm{~mm}^{2}$} \\
\cline { 2 - 5 } & \multicolumn{3}{|c|}{ Force $\mathrm{P}_{\mathrm{t}}[\mathrm{N}]$} \\
\cline { 2 - 5 } & handmade surface & sand-blast cleaning & handmade surface & sand-blast cleaning \\
\hline 1 & 3230.243 & 4580.718 & 3500.823 & 5498.408 \\
\hline 2 & 3021.059 & 4501.421 & 4038.446 & 5059.642 \\
\hline 3 & 3399.728 & 4553.418 & 3031.017 & 4697.395 \\
\hline 4 & 3182.038 & 4711.192 & 2827.701 & 4849.223 \\
\hline 5 & 2752.909 & 4898.991 & 2281.864 & 4763.577 \\
\hline$P_{t-m}$ & 3117.200 & 4619.150 & 3135.970 & 4973.650 \\
\hline$R_{t}$ & 15.585 & 23.246 & 15.68 & 24.868 \\
\hline
\end{tabular}

Table 3. The results for $z_{2}$

\begin{tabular}{|c|c|c|c|c|}
\hline \multirow{2}{*}{ Test piece number } & \multicolumn{4}{|c|}{ The length of lap: $\mathrm{z}_{2}=12.5 \mathrm{~mm} ; \mathrm{A}_{2}=312.5 \mathrm{~mm}^{2}$} \\
\cline { 2 - 5 } & \multicolumn{2}{|c|}{ Force $\mathrm{P}_{\mathrm{t}}[\mathrm{N}]$} \\
\cline { 2 - 5 } & handmade surface & sand-blast cleaning & handmade surface & sand-blast cleaning \\
\hline 1 & 3478.465 & 5398.833 & 3742.796 & 5549.746 \\
\hline 2 & 4284.306 & 5959.551 & 4442.110 & 6056.149 \\
\hline 3 & 3904.567 & 5591.105 & 4807.640 & 5909.373 \\
\hline 4 & 3884.153 & 5452.010 & 4362.317 & 5689.107 \\
\hline 5 & 4407.530 & 5703.114 & 4823.385 & 5878.906 \\
\hline $\mathrm{P}_{\mathrm{t}-\mathrm{m}}$ & 3991.800 & 5620.920 & 4435.650 & 5816.660 \\
\hline $\mathrm{R}_{\mathrm{t}}$ & 12.773 & 17.987 & 14.194 & 18.613 \\
\hline
\end{tabular}


Table 4. The results for $z_{3}$

\begin{tabular}{|c|c|c|c|c|}
\hline \multirow{2}{*}{ Test piece number } & \multicolumn{4}{|c|}{ The length of lap: $\mathrm{z}_{2}=16 \mathrm{~mm} ; \mathrm{A}_{3}=400 \mathrm{~mm}^{2}$} \\
\cline { 2 - 5 } & \multicolumn{3}{|c|}{ Araldite 2011 } & horce $\mathrm{P}_{\mathrm{t}}[\mathrm{N}]$ \\
\cline { 2 - 5 } & handmade surface & sand-blast cleaning & Araldite 2014-1 \\
\hline 1 & 4193.315 & 6061.828 & 4843.896 & 6256.972 \\
\hline 2 & 3897.565 & 5792.773 & 4361.675 & 6021.921 \\
\hline 3 & 4143.484 & 5813.575 & 4353.719 & 6302.023 \\
\hline 4 & 4130.527 & 6163.991 & 3762.965 & 6220.482 \\
\hline 5 & 4070.587 & 5780.942 & 3500.831 & 6656.479 \\
\hline $\mathrm{P}_{\mathrm{t}-\mathrm{m}}$ & 4087.100 & 5992.620 & 4164.620 & 6291.580 \\
\hline $\mathrm{R}_{\mathrm{t}}$ & 10.218 & 14.807 & 10.412 & 15.729 \\
\hline
\end{tabular}

Table 5. The results for $z_{4}$

\begin{tabular}{|c|c|c|c|c|}
\hline \multirow{2}{*}{ Test piece number } & \multicolumn{4}{|c|}{ The length of lap: $\mathrm{z}_{4}=24 \mathrm{~mm} ; \mathrm{A}_{4}=600 \mathrm{~mm}^{2}$} \\
\cline { 2 - 5 } & \multicolumn{3}{|c|}{ Araldite 2011} & \multicolumn{2}{c|}{ Araldite 2014-1 } \\
\cline { 2 - 5 } & handmade surface & sand-blast cleaning & handmade surface & sand-blast cleaning \\
\hline 1 & 5693.161 & 7842.041 & 4364.676 & 8202.019 \\
\hline 2 & 6573.163 & 7748.961 & 4734.915 & 8205.555 \\
\hline 3 & 4785.892 & 7546.047 & 4221.458 & 8259.362 \\
\hline 4 & 5127.682 & 8442.654 & 4402.663 & 7965.750 \\
\hline 5 & 5397.028 & 7969.401 & 3983.050 & 8317.146 \\
\hline$P_{t-m}$ & 5515.380 & 7909.820 & 4341.350 & 8189.700 \\
\hline$R_{t}$ & 9.192 & 13.183 & 7.236 & 13.650 \\
\hline
\end{tabular}
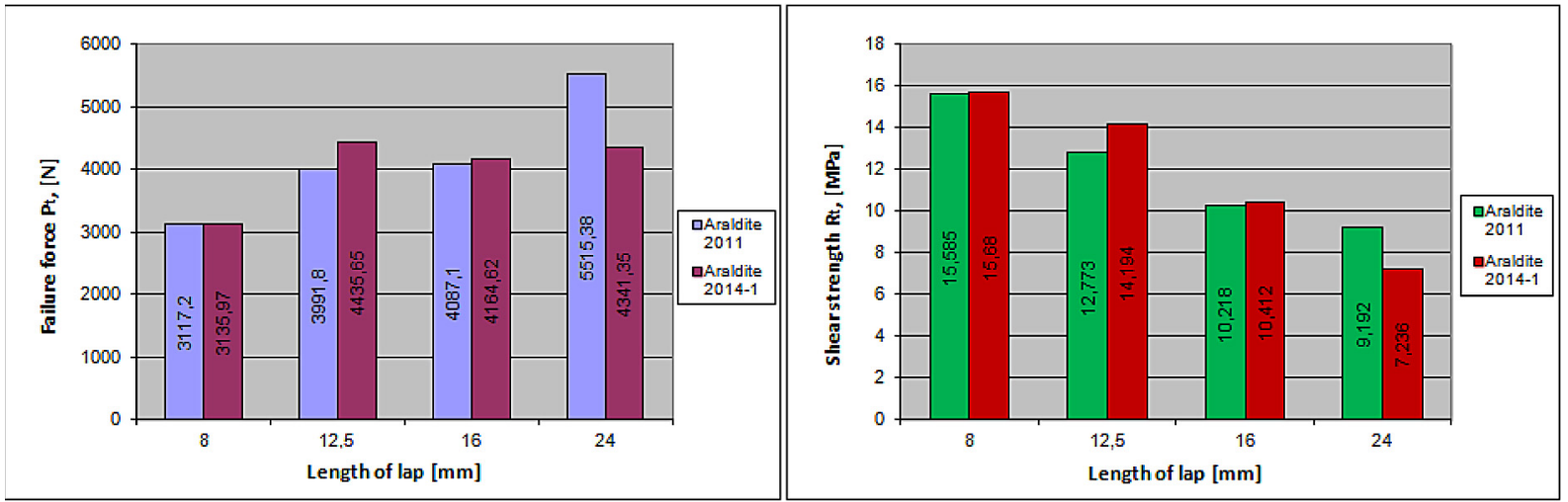

Fig. 2. Influence of length of lap on failure force (a) and static shear strength (b) of single lap adhesive joints which surfaces were prepare by treated by abrasive paper P 80
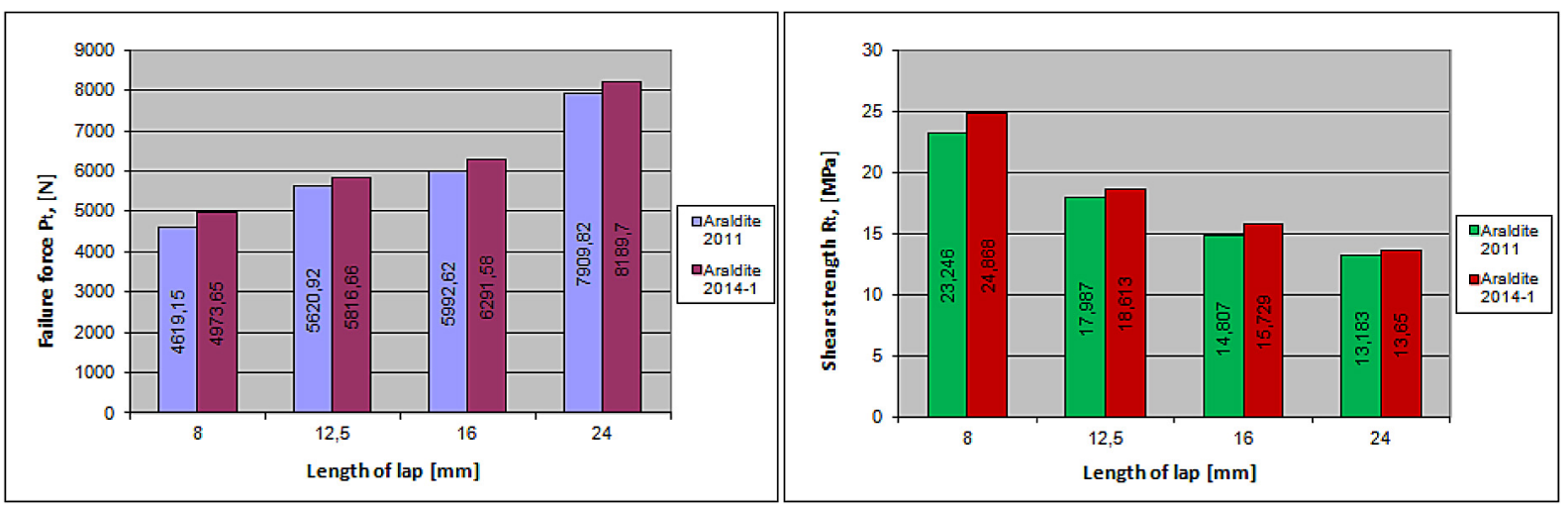

Fig. 3. Influence of length of lap on failure force (a) and static shear strength (b) of single lap adhesive joints which surfaces were prepare mechanically by sand-blast cleaning (corundum A90) 
show graphic interpretation of influence of length of lap on failure force and static shear strength for both used adhesives and surface preparation methods (Figures 2 and 3).

\section{CONCLUSIONS}

The length of lap has influence on the value of shear force and shear strength of single-lap joints. With the growth of lap size the value of shear force also increases. It has a direct relation with the growth of field of the lap. The shear strength decreases with the increase of length of the lap.

From the experiment it follows that with the same valued parameters of gluing by the epoxy resins Araldite 2011 and 2014-1 the shear strength has not great differences between values.

Significant influence on achieved static shear strength with the same length of the laps has the manner of preparing the surfaces before gluing. In the case of sand-blasting the value of force was several times higher than in the case of handmade cleaning with the abrasive paper use. From this point of view the surface pretreatment has influence on the achieved results (not only joint construction).

\section{REFERENCES}

1. Mirski Z., Piwowarczyk T.: Podstawy klejenia, kleje i ich właściwości. Przegląd Spawalnictwa 8, 2008.

2. Czaplicki J., Ćwikliński J., Godzimirski J., Konar P.: Klejenie tworzyw sztucznych. WKŁ, Warszawa 1987.

3. Godzimirski J., Kozakiewicz J., Łunarski J., Zielecki W.: Konstrukcyjne połączenia klejowe elementów metalowych w budowie maszyn. OWPP, Rzeszów 1997.

4. Porębska M., Skorupa A.: Połączenia spójnościowe. PWN, Warszawa 1993.

5. Kłonica M., Kuczmaszewski J.: Ozonowanie stali 316L na potrzeby klejenia. TAiM, 2, 2014.

6. Kuczmaszewski J., Rudawska A.: Klejenie blach ocynkowanych, WUPL. Lublin 2005.

7. Bastian H.W.: Technika zamocowań: kołki, śruby, nity, zszywki, klejenie. Arkady, Warszawa 1996.

8. Cagle Ch.V.: Kleje i klejenie. WNT, Warszawa 1977.

9. Godzimirski J.: Wytrzymałość doraźna konstrukcyjnych połączeń klejowych. WNT, Warszawa 2002.

10. Godzimirski J., Komorek A., Rośkowicz M., Smal T., Tkaczuk S.: Tworzywa adhezyjne: zastosowanie w naprawach sprzętu technicznego. WNT, Warszawa 2010.

11. www.huntsman.com (access 14.01.2015)

12. www.saarstahl.com (access 14.01.2015) 